This item was submitted to Loughborough's Research Repository by the author.

Items in Figshare are protected by copyright, with all rights reserved, unless otherwise indicated.

\title{
A study of indentation behaviour of sandwich panels supported rigidly
}

\section{PLEASE CITE THE PUBLISHED VERSION}

https://doi.org/10.1108/IJSI-01-2016-0004

\section{PUBLISHER}

(C) Emerald

\section{VERSION}

AM (Accepted Manuscript)

\section{PUBLISHER STATEMENT}

This work is made available according to the conditions of the Creative Commons Attribution-NonCommercialNoDerivatives 4.0 International (CC BY-NC-ND 4.0) licence. Full details of this licence are available at: https://creativecommons.org/licenses/by-nc-nd/4.0/

\section{LICENCE}

CC BY-NC-ND 4.0

\section{REPOSITORY RECORD}

Zhou, Gang, B. Zhang, and A. Pasricha. 2016. "A Study of Indentation Behaviour of Sandwich Panels Supported Rigidly". figshare. https://hdl.handle.net/2134/21051. 


\title{
A STUDY OF INDENTATION BEHAVIOUR OF SANDWICH PANELS SUPPORTED RIGIDLY
}

\author{
G. Zhou ${ }^{*}$ \\ Department of Aeronautical and Automotive Engineering, Loughborough University, \\ Loughborough, Leicestershire, LE11 3TU, UK \\ G.Zhou@Lboro.ac.uk \\ B. Zhang \\ Department of Aeronautical and Automotive Engineering, Loughborough University, \\ Loughborough, Leicestershire, LE11 3TU, UK \\ A. Pasricha \\ Department of Aeronautical and Automotive Engineering, Loughborough University, \\ Loughborough, Leicestershire, LE11 3TU, UK
}

\begin{abstract}
The indentation behaviour of sandwich panels is affected by a variation of a large number of both intrinsic and extrinsic parameters. It is thus challenging not only to identify those parameters that dominate the indentation behaviour but also to ascertain how they influence the indentation behaviour across all applications. In this work, we focus on an occurrence of incipient damage in rigidly-supported laminate-skinned sandwich panels under indentation. Sandwich panels were constructed with aluminium honeycomb core and carbon/epoxy skins of two different thicknesses and lay-ups and were tested quasistatically using hemispherical indentor. The effects of varying the loaded skin thickness, skin lay-up, indentor diameter and panel support conditions on initial critical load and incipient damage mechanisms have been examined. We've found that (1) the mechanisms of incipient damage induced in all ten groups of sandwich panels were combined delamination in the loaded skin laminate and buckled honeycomb cells without debonding and there were clear indications that induced local stresses were dominated by ILS stress of the skin laminates and through-the-thickness compressive strength of aluminium honeycomb core; (2) varying the thickness of the loaded laminate skin has got a profound influence over the indentation behaviour of the sandwich panels in terms of critical load, critical indentation and initial stiffness; (3) the increase of indentor diameter had the substantial effect on the indentation behaviour of the sandwich panels; (4) varying either the lay-up of the loaded skin laminates or support conditions had very little effect on the indentation behaviour.
\end{abstract}

Keywords: Indentation; Contact; Sandwich panel; Incipient damage; Quasi-static load.

\footnotetext{
*Corresponding author. G.Zhou@Lboro.ac.uk
} 


\section{Introduction}

Sandwich construction has been used in many structural applications in aircraft, helicopters, racing cars, land vehicles, ships, rail carriages and wind energy turbine blades. These sandwich structures could be vulnerable during service to localised loads such as local impacts via solid objects. Although some of them are designed against local damage to some extent, unlike in monolithic laminates, little is known to a detailed initial transition of local interaction between the loader and the loaded sandwich up to an incipient damage - the indentation behaviour. In particular, such indentation behaviour, if not accounted for in structural design, could have a significant impact on damage initiation. Unlike monolithic laminates, at present there is no such indentation law established for sandwich structures, though various investigations were reported (Chai et al 2011). To ultimately develop an indentation law, both intrinsic and extrinsic parameters that dictate indentation behaviour must be understood leading to an incipience of damage. However, this is tremendously challenging, as indentation behaviour depends on a very large number of parameters. Moreover, the specific effects of some of these parameters may depend on the features of other parameters. This work is intended to investigate the effects of some selected parameters including indenter diameter, skin thickness and a lay-up of the loaded skin laminate and panel support on the indentation behaviour of honeycomb sandwich panels with intent to ultimately establish an indentation law, in which the contributions of both laminate skin and core are identifiable via their mechanical properties.

Williamson et al (1994) tested various low-density nomex sandwich panels to ultimate failure. With combinations of different carbon/epoxy skin thicknesses, core thicknesses, two support conditions and hemispherical indentors of three different diameters, the authors found that a switching of rigid support to the two-sided clamping support did not have any effect on loadindentation response or damage mechanisms. The increase of core thickness was shown to reduce the incipient loads of core crushing damage. The authors also reported that increasing a skin thickness of these thin-skinned sandwich panels led to the increase in the incipient damage loads. In addition, the increase of indentor diameter from $12.7 \mathrm{~mm}$ to $38.1 \mathrm{~mm}$ was shown to increase the incipient critical loads. Raju et al (2001) examined the effects of different laminate skin materials and thicknesses, core thickness and indentor diameters on the indentation behaviour of rigidly supported nomex sandwich panels with constant lowdensity core. They showed that increasing indentor diameter from $6.35 \mathrm{~mm}$ to $76.2 \mathrm{~mm}$ increased the critical loads that corresponded to core crushing in the E-glass/epoxy skinned panels. The increase of skin thicknesses in carbon/epoxy skinned panels was shown to increase the core crushing critical loads, though the critical transitions in the indentation response curves seemed to be blunted out. Doubling the core thickness in panels with Eglass/epoxy skins was shown to increase the incipient loads of core crushing damage using an indentor of $76.2 \mathrm{~mm}$ diameter. Zhou et al (2007) studied the indentation behaviour of carbon/epoxy skinned sandwich panels with various combinations of skin thicknesses with either aluminium or nomex core under two different support conditions using indentors with both hemispherical and flat-ended nose shapes. They found that the first two modes of three damage mechanisms such as core crushing and skin delamination dominated the damage initiation, which was influenced by the variations and combinations of loaded skin thickness, core density and indentor nose shape. The authors showed that the increase of skin thicknesses increased the initial critical loads, with bare cores as references, which were accompanied by different damage mechanisms. Such increase was almost linear when the flat-ended indentor was used and the corresponding initial damage mechanism was core 
crushing. When core density was much higher with 4 ply skin, skin shear-out occurred under flat-ended indentor. On the contrary, with the hemispherical indentor, increase was accompanied by a slight exponential nonlinearity and the initial damage mechanism was combined core crushing and skin delamination. The increase of core density from 50 to 90 $\mathrm{kg} / \mathrm{m}^{3}$ increased the initial critical loads almost linearly under flat-ended indentor but had the marginal effect on the initial critical loads under hemispherical indentor. A switching of indentor nose shape had the very significant effect not only on the initial critical loads but also on the incipient damage mechanisms with combined core crushing and skin delamination for hemispherical nose and core crushing for flat-ended. A substitution of aluminium core material with nomex for the same core thickness and similar density made very small difference in terms of initial critical load and incipient damage mechanism. Flores-Johnson et al (2011) investigated the indentation behaviour of various PMI foam rectangular sandwich panels with woven fabric carbon/epoxy skins. They showed that the initial failure loads that corresponded to skin fracture under hemispherical indentor increased with the increase of core density of nearly four times. The increase of hemispherical indentor diameter was shown to result in the greater critical loads that corresponded to skin fracture in panels even with 51WF core. The authors also showed that the initial failure loads were not affected when the panels with 51WF core were bent, though the slopes of the load-displacement responses became substantially smaller, irrespective of the nose shape of indentor.

It is clear that the indentation behaviour of sandwich panels is affected by a variation of one of a large number of both intrinsic and extrinsic parameters. The general focus of work in the field has been on the overall bending response with little specific diagnostic interrogations of incipient damage mechanisms. An identification of parameters that dominate the indentation behaviour has been very challenging, as that is often dependent on a combination of certain parameters. To ultimately develop an indentation law, it is of paramount importance not only to identify most dominant few of parameters but also to ascertain how indentation behaviour is influenced by the variation of the identified dominant parameters. Our approach is to focus on incipient damage diagnostically in rigidly-supported carbon/epoxy laminate-skinned aluminium honeycomb sandwich panels and in this paper, we report some of experimental results of the indentation behaviour of such sandwich panels.

\section{Sandwich materials and panel manufacture}

Skin laminates were made of unidirectional LTM45/34-700 carbon/epoxy prepreg with a nominal ply thickness of $0.128 \mathrm{~mm}$ in a cross ply (CP), quasi-isotropic (QI), or multidirectional (MD) lay-up. For symmetrical panels, laminate skins that were either 8 or 16 ply thick were in a lay-up of $(0 / 90)_{2 s}$, $(0 / 90)_{4 s},(45 / 0 /-45 / 90)_{s}$, or $(45 / 0 /-45 / 90)_{2 s}$. For unsymmetrical panels, two combinations of unequal skin thicknesses were used, with one being a combination of 8 plies and 6 plies in two respective skins and the other being a combination of 16 plies and 12 plies in two respective skins. When the lay-up was quasiisotropic, the thinner skins were in a multi-directional lay-up of either $(45 / 0 /-45)_{\mathrm{s}}$ or $(45 / 0 /-$ $45)_{2 \mathrm{~s}}$. All skin laminates of $300 \times 300 \mathrm{~mm}$ were laid up and cured in an autoclave at $60^{\circ} \mathrm{C}$ under a pressure of $0.62 \mathrm{MPa}$ (90 psi) for 18 hours. A honeycomb core of aluminium 5052 H39 had a core depth of $12.7 \mathrm{~mm}$ and a density of $70 \mathrm{~kg} / \mathrm{m}^{3}$ with a cell size of $4.7625 \mathrm{~mm}$. Adhesive VTA260 with built-in nylon mesh was used for interfacial bonding and VTA260 resin was compatible with LTM45 resin, even though they were cure separately. Each skin was individually bonded to the core in an oven at $60^{\circ} \mathrm{C}$ for 6 hours under a pressure of 0.1 MPa (15 psi), following manufacturer's recommendations. Panels with 8/8 and 8/6 ply skin 
combinations were addressed as 'thin' panels for convenience and the remaining with 16/16 or 16/12 ply skin combinations were addressed as 'thick' panels.

\section{Quasi-static indentation tests}

Individual panel specimens have the dimensions of approximately $96 \times 96 \mathrm{~mm}$, after being cut out of larger panels, each of $300 \times 300 \mathrm{~mm}$. The centre on each square panel specimen was marked out for contact. The central thickness of each panel was estimated on a basis of four measurements from the middle of each side using a micrometer, though a nominal thickness of the loaded skin was known. A hemispherical nose shape was used for indentors, with three different diameters of 8,14 and $20 \mathrm{~mm}$. The largest diameter of $20 \mathrm{~mm}$ was considered to be small enough not to induce an indentation deformation, which would spread to the edges of the panels.

In an indentation test, each of the majority of panel specimens was laid on top of rigid support with a periphery area of the specimen (an outside of an opening of $80 \mathrm{~mm}$ diameter) being held down gently by a fingered-tightened metal frame, as shown in Fig. 1. In the test, the displacement of loader provided a direct measurement of indentation. A few selected specimens were subjected to a bending over an opening of $40 \mathrm{~mm}$ diameter. A universal testing machine, Mand, was used at a load rate of $2 \mathrm{~mm} /$ per min with an overall set-up. A bit of trial and error was needed at the beginning to establish approximately an initial critical load when an incipient damage was likely to occur, which was dependent on the specific details of sandwich constructions. Subsequent tests were stopped once an incipient damage was believed to have occurred. A total of ten groups of tests were conducted with results being summarised in Tables 1 and 2. As the distal skins of those indentation specimens did not make any contribution to the indentation behaviour under rigid support, the test results of the specimens with $8 / 8$ ply skin arrangement were pooled with those of $8 / 6$ ply skin for the same laminate lay-up. The same exercise was applied to the 16/16 ply and 16/12 ply thick sandwich panels under rigid support.

\section{Indentation responses of sandwich panels}

As indentation behaviour primarily reflects the initial interaction between a loader and a sandwich specimen, it is thus of paramount importance that tests are stopped promptly once an initial damage occurs so that a further postmortem examination of the preserved tested specimens can be carried out to ascertain the mechanisms of the initial damage. While a slight overloading (see specimens BZ8/8CP8-9 and AP8/6CP-2 in Fig. 2) of the first specimen of each group was necessary to ensure that initial damage was induced, nevertheless, the excessive overloading was to be minimised or eliminated so that the mechanism of the initial damage was preserved for postmortem examination. Once incipient damage has taken place, its propagation has got much more complex effect on the continued indentation behaviour so that an indentation law may not be able to take it into account. Thus, typical load-indentation curves shown in Figs 2-3 have either an initial (almost) linear or nonlinear response up to the occurrence of incipient damage when the loads dropped either smoothly or sharply. These loads were defined accordingly as critical loads. Ensuring the occurrence of the initial damage beyond critical loads allowed loading to continue until the respective cut-off (last) points of the curves. 
Representative load-indentation curves are shown in Figs 2-3. For thin panels with 8 ply skin, the initial responses induced by $8 \mathrm{~mm}$ indentor in Fig. 2 are almost linear. This combination (8 ply skin with $8 \mathrm{~mm}$ diameter loader) among all combinations showed some variations among these tests in their indentation behaviour in terms of indentation and slopes. As the ability of the 8 ply skin to spread the local pressure to a larger area was limited, a more localised resistance was expected to be accompanied by this variation. Moreover, a precise positioning of apex on the hemispherical nose of the indentor through the skin could not be controlled so that the centre of the transmitted pressure could be over the top of a node, freewall, node-freewall joint, or the middle of a cell of honeycomb with a cell size of 4.7625 $\mathrm{mm}$. A possibility of several positioning combinations, as demonstrated by Zhou et al (2007), could contribute directly to the variations of the indentation and stiffness results shown in Fig. 2, to some extent. Under a larger indentor of $20 \mathrm{~mm}$ diameter, the overall characteristics of indentation responses are very similar. Moreover, the critical loads from these thin panels did not drop much, as fewer cells underneath were crushed. Beyond the critical load, the occurrence of the incipient damage severely degraded the flexural rigidity of the panels so that subsequent responses have much smaller slopes, as expected.

For thick panels with 16 ply skin, the degree of nonlinearity in their initial responses in Fig. 3 became less, as the ability of the 16 ply skin to spread the local pressure to a larger area was much greater with the much greater corresponding critical loads. Consequently, the indentation behaviour was, again, much less varying. In particular, a dropping of the critical loads from these thick panels was much more pronounced than that of the thin panels, as more cells underneath were involved in crushing and much more strain energy was released at the moment of the occurrence of the incipient damage. The greater critical loads were also accompanied by the marginally greater magnitudes of indentation, which again confirms that a greater number of cells were involved in crushing. Beyond the critical load, again, the occurrence of the incipient damage severely degraded the flexural rigidity of the panels, which is demonstrated via the much reduced slopes of the second stage responses, as expected. Because of the significant load-drop, which was easily picked up during testing, none of the specimens with 16 ply skin was overloaded.

Allowing selected thick specimens to bend over an opening of $40 \mathrm{~mm}$ diameter with $8 \mathrm{~mm}$ diameter loader did not have much effect on the indentation responses shown in Fig. 4, as very similar features were easily observed. This change of the boundary supports had little effect on either critical loads or the incipient damage mechanisms (see Fig.10). This could have a lot to do with the fact that the sandwich specimens under bending had the clamping plate finger-tightened so that the induced membrane effect was pretty much negligible. The bending behaviour of these panels was still largely influenced by its local flexural rigidity.

In Fig. 5, it can be seen that the moderate increase in indentor diameter did not have any influence over the responses of thin sandwich panels. This is in agreement with the early observations of these panels, unlike in Raju et al (2001). When the thickness of the loaded skin in sandwich panels was doubled, the larger diameters had slightly greater critical loads, as shown in Fig. 6 (see also Fig. 13). This was expected, as the thicker skins were able to spread the local pressure to a much greater area, thereby storing more strain energy. The latter increased the resistance of the panels to the occurrence of incipient damage without much change of indentations, which is somewhat in agreement with Raju et al (2001). 
The variation of the thickness of the loaded skin has got an overwhelming effect on the indentation responses as shown in Fig. 7, irrespective of indentor diameter. This enhancement was manifested in critical loads, slopes and indentations. It is clear that the thickness of the loaded skin could play the most significant role in the development of indentation law for sandwich structures.

The effect of lay-up of the loaded skin laminate on the indentation responses is small, as shown in Fig. 8, from a thick panel with a small but visible increase in critical load. It is very interesting to observe that although the flexural rigidity of the cross-ply skin is greater than that of the quasi-isotropic skin, the identical slopes from the indentation responses of both thin and thick panels indicate that the flexural rigidity of the sandwich itself made the greater impact globally and varying the lay-up of the loaded skin laminate had only some localised effect.

\section{Incipient damage mechanisms in sandwich panels in the $90^{\circ}$ direction of the loaded skin laminate}

After testing, all the tested specimens were cut up initially in the direction of $90^{0}$ in the lay-up of the loaded skin laminate and of the width of the honeycomb core with one side of saw blade right on a diametrical line. No further polishing of the cut-up surfaces was necessary, as buckled or crushed cells were evident and damage mechanism in the loaded skin was very much visible under a low power optical microscope of 25 time magnification. Thus the 'half' parts of all the cut-up specimens were retained for visual observations, as the saw blade removed a strip of the material of about $2.2 \mathrm{~mm}$ thick in the other parts of the remaining. The overall damage characterisations observed on such diametrical cross sections are summarised in Table 1 for thin panels and Table 2 for thick panels.

Extensive observations on the cut cross sections of the half specimens $\left(90^{0}\right)$ show that the mechanism of the incipient damage was combined single delamination in the loaded skin and core crushing right under the loaded skin, irrespective of skin thickness, skin lay-up, indentor diameter, or support condition. A few thin panels which were tested first with little or small load drops had two delaminations because substantial overloading was allowed to ensure the occurrence of incipient damage (e.g. see photograph in Fig. 9). Photographic evidence of delamination and buckled honeycomb cells is shown in Figs 9-12 for representing all groups of the specimens. This finding on the mechanism of the incipient damage is very similar to the earlier findings of sandwich panels loaded in bending under both quasi-static (Zhou et al (2006)) and impact (Zhou et al (2009)) loads. Nevertheless, the variations of skin thickness, skin lay-up, indentor diameter and support condition did have the substantial effects on the extent of and through-the-thickness location of delamination as well as the number of cells being crushed. One common feature is that delamination occurred between the mid-plane of the loaded skin and skin-core bonding interface in all cases, with no failure at the bonding interface (i.e. debonding). Moreover, the extent of crushed cells is much greater than that of delamination. For thin panels, the smaller indentor diameter, the closer to the bonding interface the through-the-thickness location of delamination occurrence. That is, the average location of delamination was at 7/8 interface for $8 \mathrm{~mm}$ diameter indentor, 6/7 interface for 14 $\mathrm{mm}$ diameter and 5/6 for $20 \mathrm{~mm}$ indentor. In the meanwhile, the average number of buckled or crushed honeycomb cells increased incrementally from 2.30, 2.75, to 3.05, which are equivalent to the circular area of $10 \mathrm{~mm}$ to $15 \mathrm{~mm}$. Although the variation of indentor diameter was found to have little noticeable effect on the indentation responses earlier, it still 
had some influence over type of local stresses, among which interlaminar shear stresses (ILS) were promoted sufficiently to induce delamination in the loaded skin laminates. This upshifting of the delamination location towards the mid-plane with the increase of indentor diameter suggests that when sandwich panels were not allowed to bend, their indentation behaviour could be dictated very much by the performance of the loaded skin coupled with the characteristics of 'core support' underneath, though the through-the-thickness shear stresses were highest at the bonding interface, if a bending of the sandwich panels was allowed. When local compressive pressure was well spread, the loaded skins could almost behave like short laminate beams.

For thick panels (with a total of 16 plies in the loaded skin), all occurrences of delamination, when ply number counting started from the top surface, were between the $11^{\text {th }}$ ply and $16^{\text {th }}$ ply (one that was bonded to core), with no debonding at the bonding interface. They almost all are within the fourth quarter in the through-the-thickness direction, with the average location of delamination occurrence being at the 14/15 ply interface, irrespective of indentor diameter, ply lay-up, or panel support condition. This suggests that for sandwich panels with constant core density, the thickness of the loaded skin, when it reaches certain level, could completely dominate their indentation behaviour. Since such thick skin thickness could spread the local pressure uniformly over a larger area, similarly, the number of buckled or crushed honeycomb cells varied from 2 from 4, which are equivalent to the circular area of $10 \mathrm{~mm}$ to $20 \mathrm{~mm}$, which is slightly larger than that of thin panels.

\section{Parametric study on indentation behaviour}

\subsection{Effect of loaded skin thickness on indentation behaviour}

Since the respective extents of delamination and buckled cells depended on the level of cutoff loads, here discussion on the effect of the loaded skin thickness on the indentation behaviour is restricted to critical loads, which was normalised with regard to the number of plies in each skin. It can be seen in Fig. 13 that when the number of plies in the loaded skin with the same lay-up was doubled and was loaded with the same indentor, there was significant additional enhancement in critical loads, namely, 21\% for $8 \mathrm{~mm}$ diameter indentor and $32 \%$ for $20 \mathrm{~mm}$ diameter indentor for panels with skin laminates in a cross-ply lay-up. Load enhancement of $19 \%$ was achieved in panels with skin laminates in a quasi-isotropic lay-up. On the contrary, critical indentations in all three cases were worse off by similar amounts with respect to a linear scaling, namely, 27\%, 33\% and 23\%, though the respective magnitudes of the critical indentations increased, after doubling the loaded skin thickness.

\subsection{Effect of indenter diameter on indentation behaviour}

An increase of indentor diameter tends to spread the contact area and thereby reduce the degree of normal stress concentration. This should enhance the indentation resistance. For thin panels, this enhancement of 14\% from $8 \mathrm{~mm}$ indentor to $20 \mathrm{~mm}$ indentor appears to be marginal, as shown in Fig. 14. Enhancements in critical loads in thick panels vary from modest (13\%, up to $19 \%$ for $14 \mathrm{~mm}$ indentor) in a quasi-isotropic skin to significant (24\%, up to $30 \%$ for $14 \mathrm{~mm}$ indentor). A very significant additional effect of increasing indentor diameter was the upward shifting of the through-the-thickness location of delamination occurrence towards the mid-plane. 


\subsection{Effect of skin lay-up on indentation behaviour}

A change of laminate lay-up in the loaded skin should alter the flexural rigidity of the skin primarily and thereby the sandwich panels, to some extent. Nevertheless, as discussed earlier, its effect on critical loads for both thin and thick panels is very small, as indicated in Tables 1 and 2 . This may well be because the indentation magnitude of the loaded laminate skins was small.

\subsection{Effect of specimen support on indentation behaviour}

In the indentation process, the local resistance of panel specimens came entirely from the bending resistance of the loaded (top) skin and the normal resistance of core, whereas the distal skin that rested on the rigid support did not make any contribution. As a consequence, a loading of indentor tended to just bend the skin, which in turn compressed the core underneath. When the skin constrained to the core via bonding was sufficient thick, the bending deformation was spread, via the skin, over an area that was larger than the contact area. Allowing about $17 \mathrm{~mm}$ thick panel specimens to bend introduced a structural response into the local indentation behaviour, even though the structural response could be very limited with a circular opening of only $40 \mathrm{~mm}$ diameter under an indentor diameter of $8 \mathrm{~mm}$. The flexural rigidity of the panels in bending influences the initial response up to the incipient damage. Nevertheless, altering the support conditions under current experimental set-up had a negligible effect on both critical load and loader displacement as shown in Table 2.

\section{Conclusions}

The indentation behaviour of sandwich panels has been investigated with focus on the variation of loaded skin thickness and skin laminate lay-up, indentor diameter and support conditions. It was found that (1) the mechanisms of incipient damage induced in these sandwich panels were combined delamination in the loaded skin laminate and buckled honeycomb cells without debonding, (2) varying the thickness of the loaded skin has got a profound influence over the indentation behaviour in terms of critical load, critical indentation and initial stiffness, (3) the increase of indentor diameter had the substantial effect on the indentation behaviour and (4) varying either the lay-up of the loaded skin laminates or support conditions had very little effect on the indentation behaviour. There were clear indications that induced local stresses were dominated by ILS stress of the skin laminates and throughthe-thickness compressive strength of honeycomb core. It is also significant to notice that it is just one (loaded) skin that will dictate the indentation behaviour. These highlight the profound fundamental difference in indentation behaviour between monolithic laminates and sandwich panels.

\section{Acknowledgement}

Mr Zhicheng Wang on leave from Shanghai Research Institute of Mechanical and Electrical Engineering, China helped with some experimental work and redrew Figure 1.

\section{References}


Chai, G.B. and Zhu, S. (2011), “A review of low-velocity impact on sandwich structures”, Proceedings of the Institution of Mechanical Engineers Part L: Journal of Materials Design and Applications, Vol 225, pp. 207-230.

Williamson, J.E. and Lagace, P.A. (1994), "Response mechanisms in the impact of graphite/epoxy honeycomb sandwich panels", Proceedings of the $8^{\text {th }}$ American Society for Composite Materials Conference, pp. 287-297.

Raju, K.S. and Tomblin, J.S. (2001), "Damage characteristics in sandwich panels subjected to static indentation using spherical indentors”, Proceedings of the 42nd AIAA/ASME/ASCE/AHS/ASC Structures, structural dynamics, and materials conference 2001, Paper No. AIAA 2001-1189.

Zhou, G., Hill, M.D. and Hookham, N. (2007), "Investigation of parameters governing the damage and energy-absorbing characteristics of honeycomb sandwich panels”, Journal of Sandwich Structures and Materials, Vol 9, pp. 309-342.

Flores-Johnson, E.A. and Li, Q.M. (2011), "Experimental study of the indentation of sandwich panels with carbon fibre-reinforced polymer face sheets and polymeric foam core”, Composites: Part B, Vol 42, pp. 1212-1219.

Zhou, G., Hill, M.D. and Hookham, N. (2006), "Damage characteristics of composite honeycomb sandwich panels in bending under quasi-static loading”, Journal of Sandwich Structures and Materials, Vol 8, pp. 55-90.

Zhou, G. and Hill, M.D. (2009), "Impact damage and residual compressive strength of honeycomb sandwich panels”, Journal of Sandwich Structures and Materials, Vol 11, pp. 329-356. 
Table 1 Summary of visual observations of cut-up thin sandwich panels in indentation test on rigid support

\begin{tabular}{|c|c|c|c|c|c|}
\hline $\begin{array}{c}\text { Specimen } \\
\text { ID }\end{array}$ & $\begin{array}{c}\text { Indenter } \\
\text { diameter }\end{array}$ & $\begin{array}{c}\text { Critical } \\
\text { load }\end{array}$ & Displ. & $\begin{array}{c}\text { No of crushed } \\
\text { cells in } \\
90^{0} \text { direction }\end{array}$ & $\begin{array}{c}\text { Delamination } \\
\text { characteristics } \\
\text { in } 90^{0} \text { direction }\end{array}$ \\
\hline- & $\mathrm{mm}$ & $\mathrm{kN}$ & $\mathrm{mm}$ & - & Ply interface size \\
\hline AP8/6CP-1 & 8 & 0.421 & 0.25 & 0 & $7 / 80.64 \mathrm{~mm}$ \\
\hline AP8/6CP-2 & 8 & 0.423 & 0.29 & 2.5 & $7 / 83.42 \mathrm{~mm}$ \\
\hline BZ8/8CP8-7 & 8 & 0.307 & 0.18 & 3.0 & $7 / 85.46 \mathrm{~mm}$ \\
\hline BZ8/8CP8-8 & 8 & 0.413 & 0.21 & 3.0 & $6 / 76.04 \mathrm{~mm}$ \\
\hline BZ8/8CP8-9 & 8 & 0.402 & 0.19 & 3.0 & $7 / 85.08 \mathrm{~mm}$ \\
\hline AP8/8CP-1 & 14 & 0.427 & 0.24 & 3.0 & $6 / 710.88 \mathrm{~mm}$ \\
\hline BZ8/8CP14-4 & 14 & 0.477 & 0.29 & 2.5 & $5 / 68.25 \mathrm{~mm}$ \\
\hline BZ8/8CP14-5 & 14 & 0.427 & 0.23 & 3.0 & $6 / 710.39 \mathrm{~mm}$ \\
\hline BZ8/8CP14-6 & 14 & 0.416 & 0.25 & 2.5 & $6 / 79.94 \mathrm{~mm}$ \\
\hline AP8/8CP-2 & 20 & 0.410 & 0.32 & 4.0 & $6 / 79.46 \mathrm{~mm}$ \\
\hline AP8/8CP-3 & 20 & 0.453 & 0.25 & 3.5 & $4 / 59.57 \mathrm{~mm}$ \\
\hline AP8/6CP-3 & 20 & 0.441 & 0.24 & 4.0 & $6 / 711.76 \mathrm{~mm}$ \\
\hline BZ8/8CP20-1 & 20 & 0.459 & 0.33 & 3.0 & $5 / 68.45 \mathrm{~mm}$ \\
\hline BZ8/8CP20-2 & 20 & 0.386 & 0.31 & 2.5 & $6 / 78.77 \mathrm{~mm}$ \\
\hline BZ8/8CP20-3 & 20 & 0.447 & 0.25 & 2.5 & $5 / 67.20 \mathrm{~mm}$ \\
\hline BZ8/6CP20-1 & 20 & 0.491 & 0.26 & 3.0 & $5 / 610.42 \mathrm{~mm}$ \\
\hline BZ8/6CP20-2 & 20 & 0.452 & 0.20 & 2.0 & $6 / 710.87 \mathrm{~mm}$ \\
\hline BZ8/6CP20-3 & 20 & 0.430 & 0.21 & 3.0 & $6 / 78.08 \mathrm{~mm}$ \\
\hline BZ8/6CP20-4 & 20 & 0.516 & 0.25 & 3.0 & $5 / 67.53 \mathrm{~mm}$ \\
\hline BZ8/6QI20-1 & 20 & 0.455 & 0.25 & 3.5 & $5 / 67.83 \mathrm{~mm}$ \\
\hline BZ8/6QI20-2 & 20 & 0.487 & 0.24 & 3.0 & $5 / 67.07 \mathrm{~mm}$ \\
\hline BZ8/6QI20-3 & 20 & 0.397 & 0.23 & 3.5 & $5 / 66.13 \mathrm{~mm}$ \\
\hline
\end{tabular}


Table 2 Summary of visual observations of cut-up thick sandwich panels in indentation test

\begin{tabular}{|c|c|c|c|c|c|c|}
\hline $\begin{array}{c}\text { Specimen } \\
\text { ID }\end{array}$ & $\begin{array}{c}\text { Support } \\
\text { condition }\end{array}$ & $\begin{array}{c}\text { Indenter } \\
\text { diameter }\end{array}$ & $\begin{array}{c}\text { Critical } \\
\text { load }\end{array}$ & Displ. & $\begin{array}{c}\text { No of crushed } \\
\text { cells in } \\
90^{0} \text { direction }\end{array}$ & $\begin{array}{c}\text { Delamination } \\
\text { characteristics } \\
\text { in 90 } 0^{0} \text { direction }\end{array}$ \\
\hline- & - & $\mathrm{mm}$ & $\mathrm{kN}$ & $\mathrm{mm}$ & - & Ply interface size \\
\hline AP16/12CP-1 & Rigid & 8 & 0.956 & 0.32 & 3.0 & $14 / 156.00 \mathrm{~mm}$ \\
\hline AP16/16CP-1 & Rigid & 8 & 0.952 & 0.33 & 2.0 & $14 / 157.59 \mathrm{~mm}$ \\
\hline AP16/12CP-2 & Rigid & 14 & 1.236 & 0.35 & 2.0 & $15 / 161.74 \mathrm{~mm}$ \\
\hline AP16/12CP-3 & Rigid & 20 & 1.145 & 0.36 & 2.0 & $14 / 151.76 \mathrm{~mm}$ \\
\hline AP16/16CP-4 & Rigid & 20 & 1.322 & 0.38 & 3.0 & $14 / 155.53 \mathrm{~mm}$ \\
\hline BZ16/12CP20-1 & Rigid & 20 & 1.123 & 0.33 & 4.0 & $14 / 1511.86 \mathrm{~mm}$ \\
\hline BZ16/12CP20-2 & Rigid & 20 & 1.155 & 0.33 & 4.0 & $13 / 1410.50 \mathrm{~mm}$ \\
\hline AP16/16QI-1 & Rigid & 8 & 0.933 & 0.30 & 2.0 & $14 / 158.15 \mathrm{~mm}$ \\
\hline AP16/16QI-2 & Rigid & 8 & 0.942 & 0.38 & 3.0 & $13 / 148.82 \mathrm{~mm}$ \\
\hline AP16/16QI-3 & Rigid & 14 & 1.040 & 0.34 & 2.5 & $12 / 138.40 \mathrm{~mm}$ \\
\hline AP16/16QI-4 & Rigid & 14 & 1.187 & 0.68 & 4.5 & $13 / 1415.86 \mathrm{~mm}$ \\
\hline AP16/16QI-5 & Rigid & 20 & 1.033 & 0.39 & 3.5 & $12 / 134.18 \mathrm{~mm}$ \\
\hline AP16/16QI-6 & Rigid & 20 & 1.171 & 0.49 & 2.0 & $12 / 134.37 \mathrm{~mm}$ \\
\hline BZ16/12QI20-1 & Rigid & 20 & 1.021 & 0.29 & 3.0 & $12 / 1312.84 \mathrm{~mm}$ \\
\hline BZ16/12QI20-2 & Rigid & 20 & 1.044 & 0.34 & 3.5 & $11 / 1211.53 \mathrm{~mm}$ \\
\hline BZ16/12QI20-3 & Rigid & 20 & 1.052 & 0.34 & 3.5 & $14 / 1510.89 \mathrm{~mm}$ \\
\hline AP16/16CP-2 & Bending & 8 & 1.067 & 0.36 & 2.5 & $14 / 154.91 \mathrm{~mm}$ \\
\hline AP16/16CP-3 & Bending & 8 & 1.051 & 0.34 & 2.0 & $14 / 154.96 \mathrm{~mm}$ \\
\hline AP16/16CP-5 & Bending & 8 & 1.281 & 0.37 & 3.0 & $15 / 166.79 \mathrm{~mm}$ \\
\hline AP16/16CP-6 & Bending & 8 & 1.322 & 0.41 & 3.0 & $14 / 154.78 \mathrm{~mm}$ \\
\hline
\end{tabular}




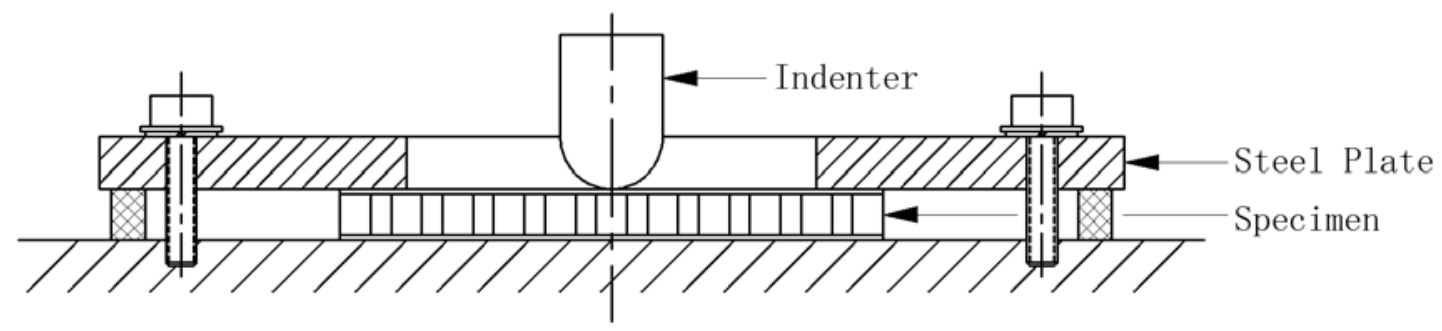

Fig. 1. An indentation test set-up of a sandwich panel on rigid support

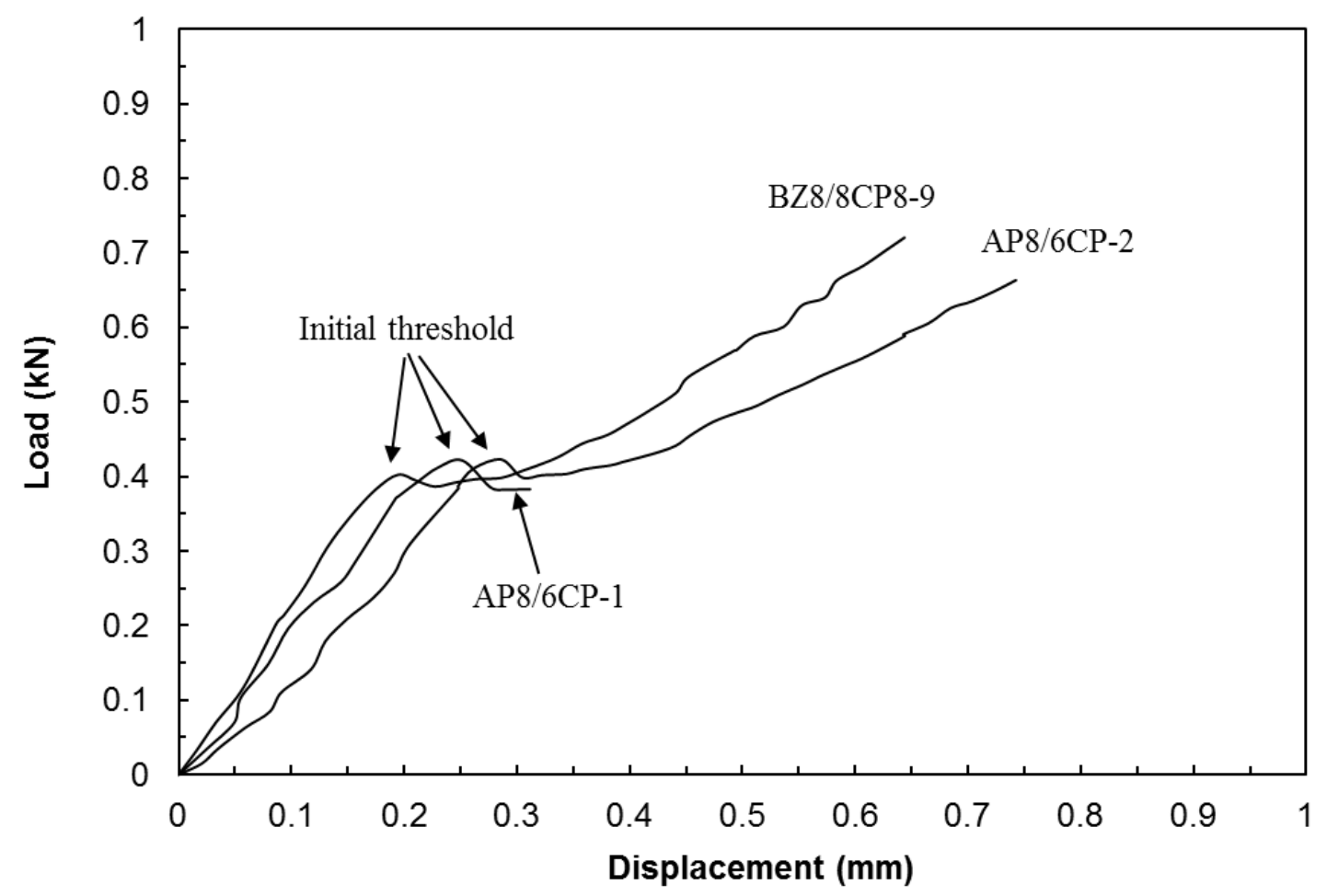

Fig. 2. Load-indentation curves of thin sandwich panels under $8 \mathrm{~mm}$ diameter indentor with rigid support 


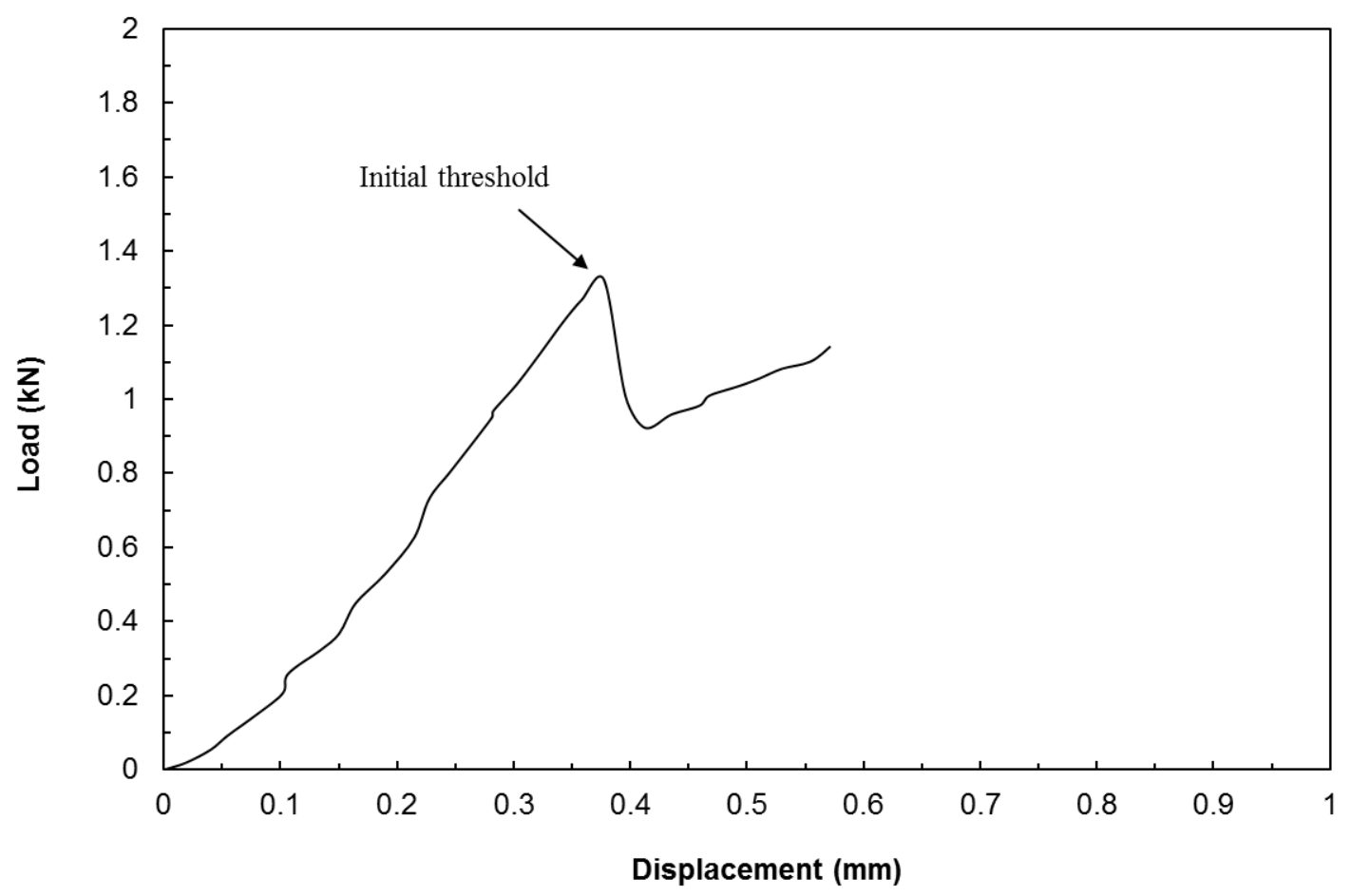

Fig. 3. Load-indentation curve of a thick panel under $20 \mathrm{~mm}$ diameter indentor with rigid support

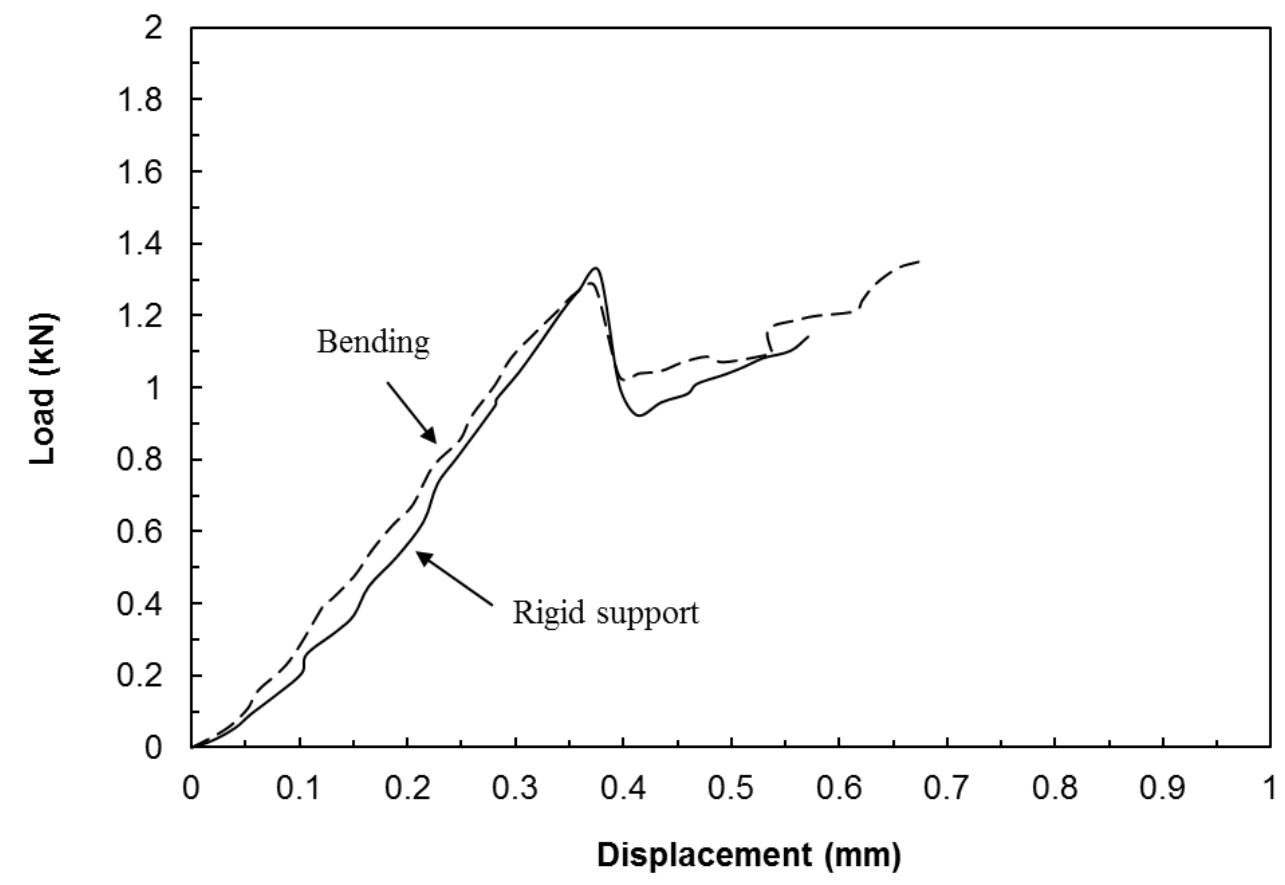

Fig. 4. Load-indentation curves of thick panels between rigid support and bending by $8 \mathrm{~mm}$ diameter indentor 


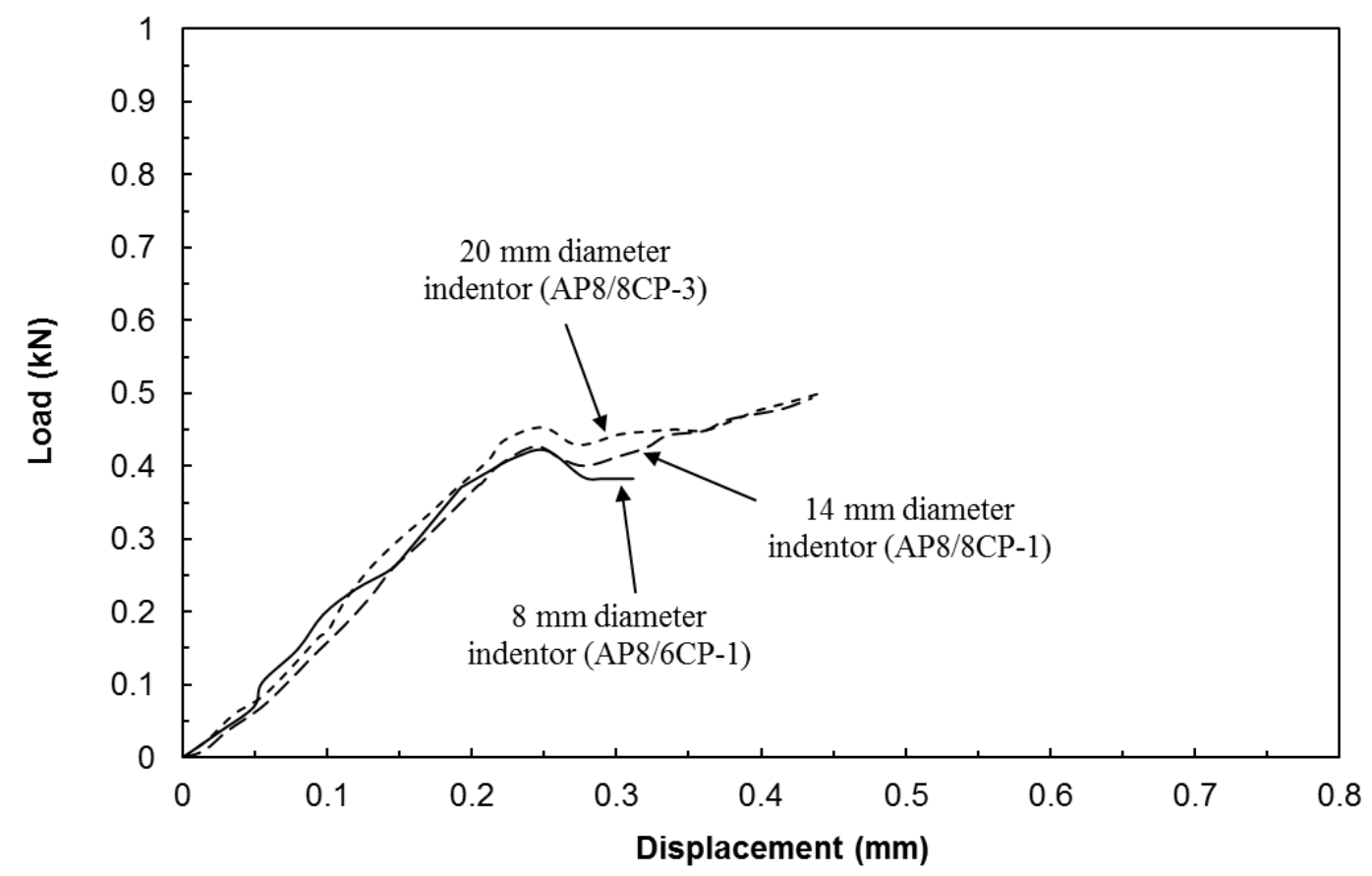

Fig. 5. Load-indentation curves of thin sandwich panels with different indentor diameters under rigid support

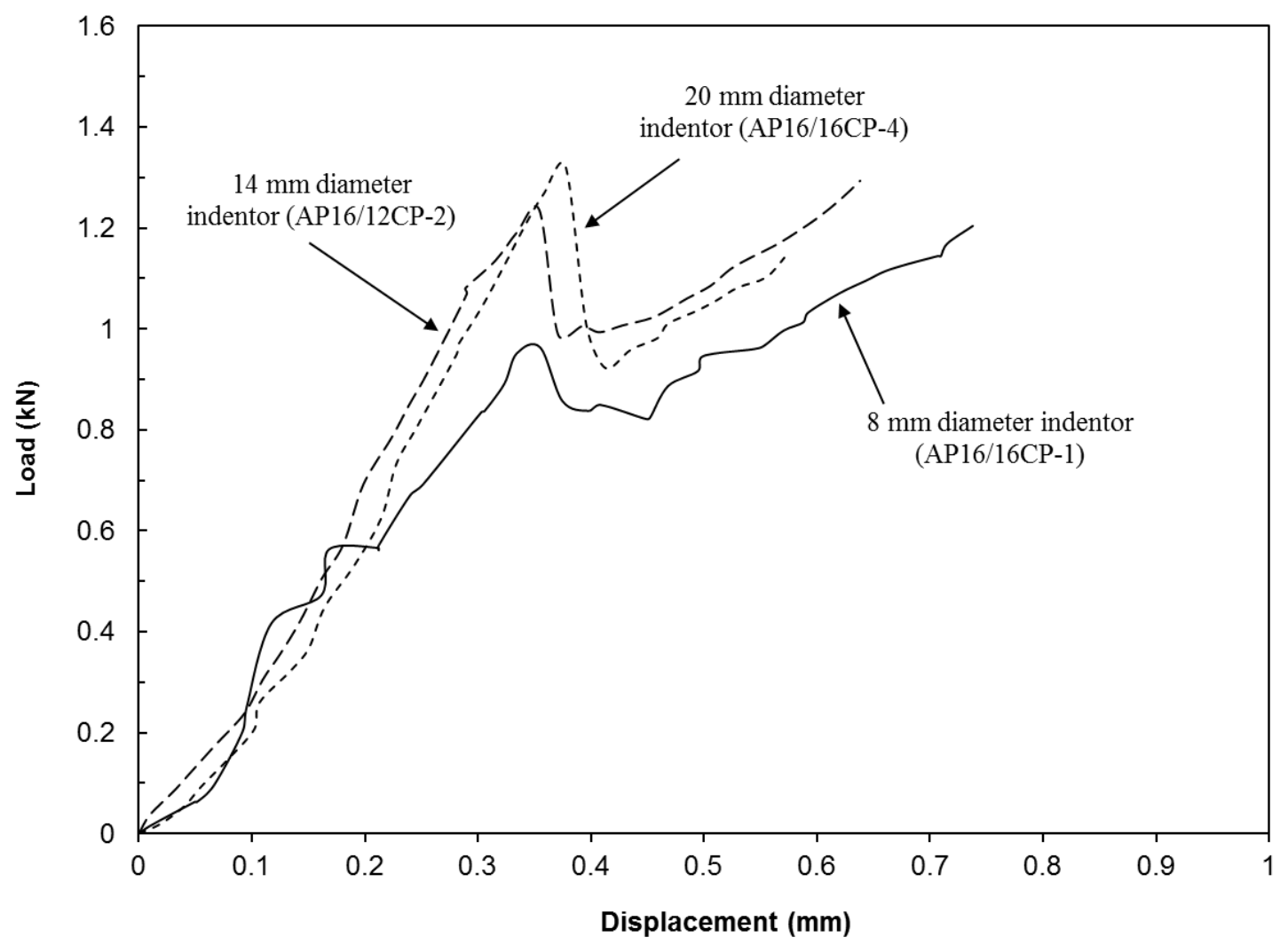

Fig. 6. Load-indentation curves of thick sandwich panels with different indentor diameters under rigid support 


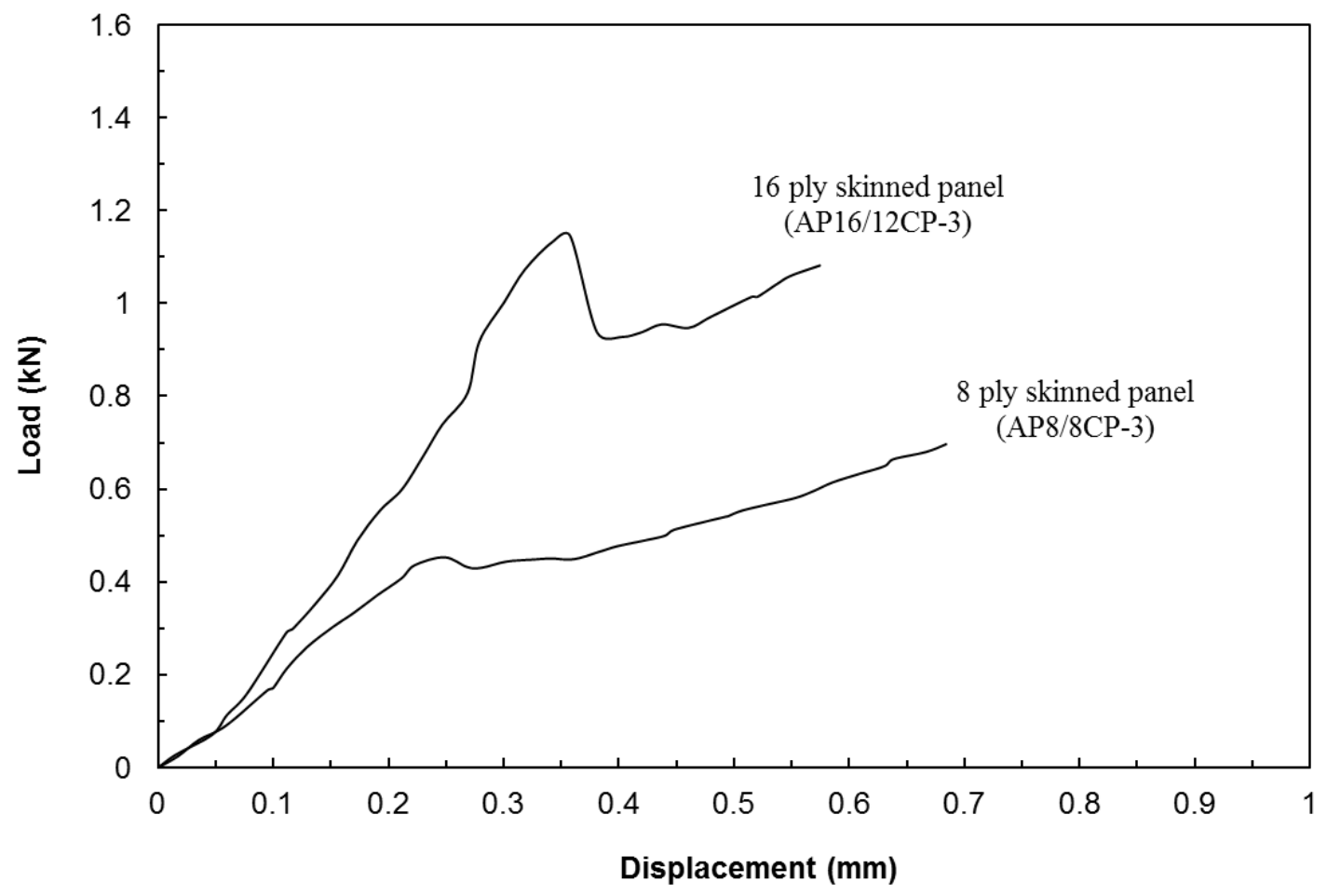

Fig. 7. Comparison of load-indentation curves of sandwich panels with different skin thicknesses under $20 \mathrm{~mm}$ diameter indentor under rigid support

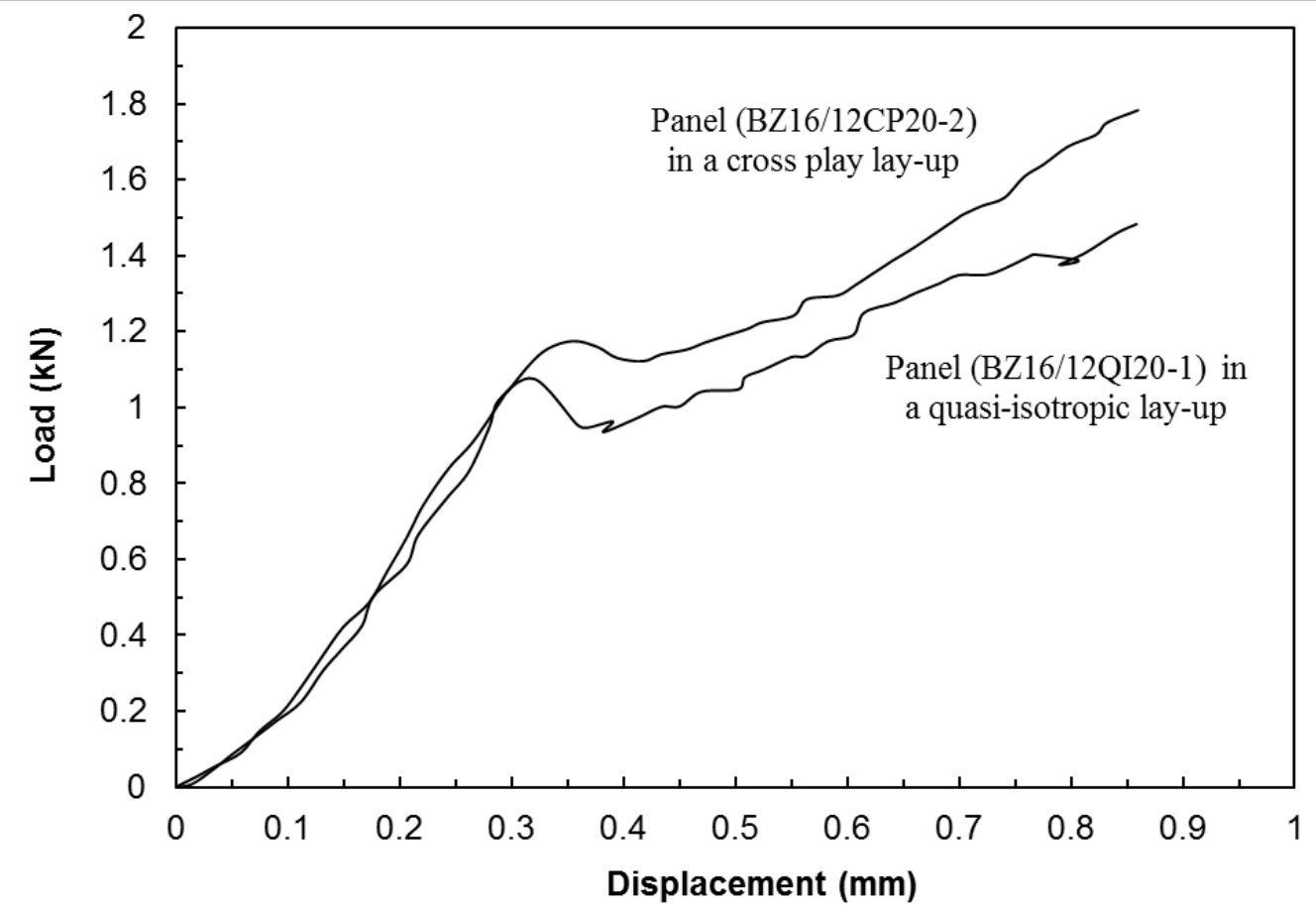

Fig. 8. Comparison of load-indentation curves of thick sandwich panels with different skin lay-ups under $20 \mathrm{~mm}$ diameter indentor under rigid support 


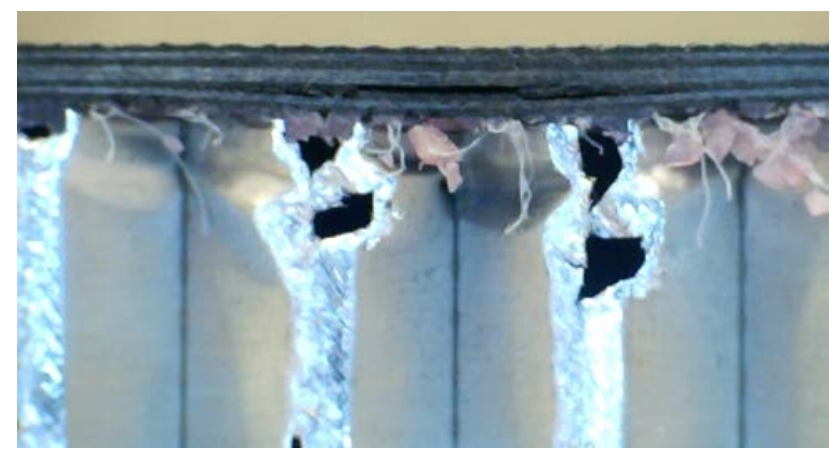

Fig. 9. A thin sandwich panel with cross ply skins under rigid support with $20 \mathrm{~mm}$ diameter indentor

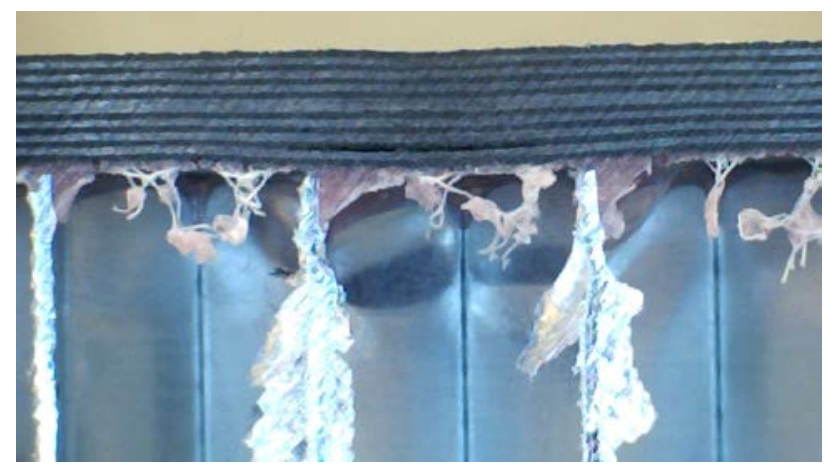

Fig. 10. A thick sandwich panel with cross ply skins under rigid support with $8 \mathrm{~mm}$ diameter indentor

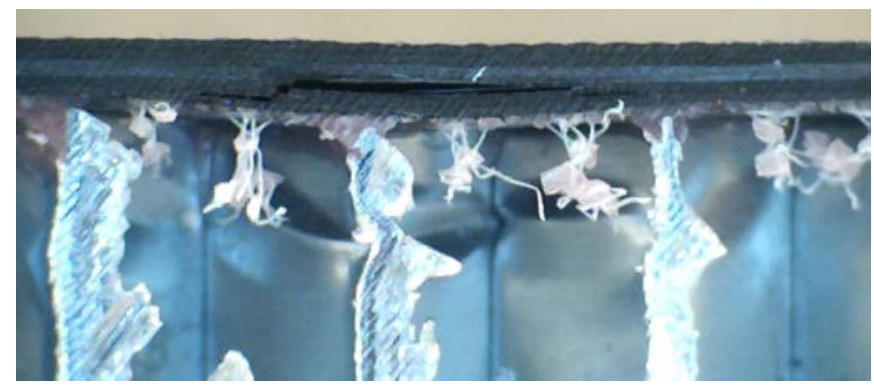

Fig. 11. A thin sandwich panel with quasi-isotropic skins under rigid support with $20 \mathrm{~mm}$ diameter indentor 


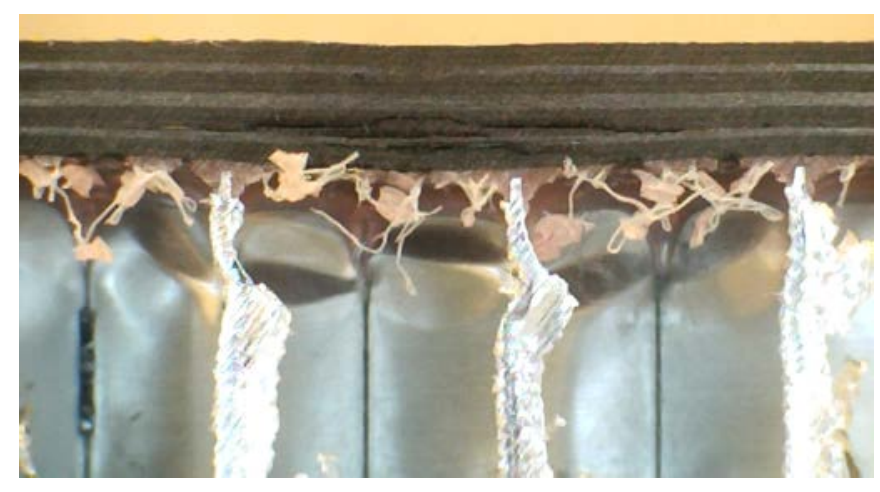

Fig. 12. A thick sandwich panel with quasi-isotropic skins under rigid support with $20 \mathrm{~mm}$ diameter indentor

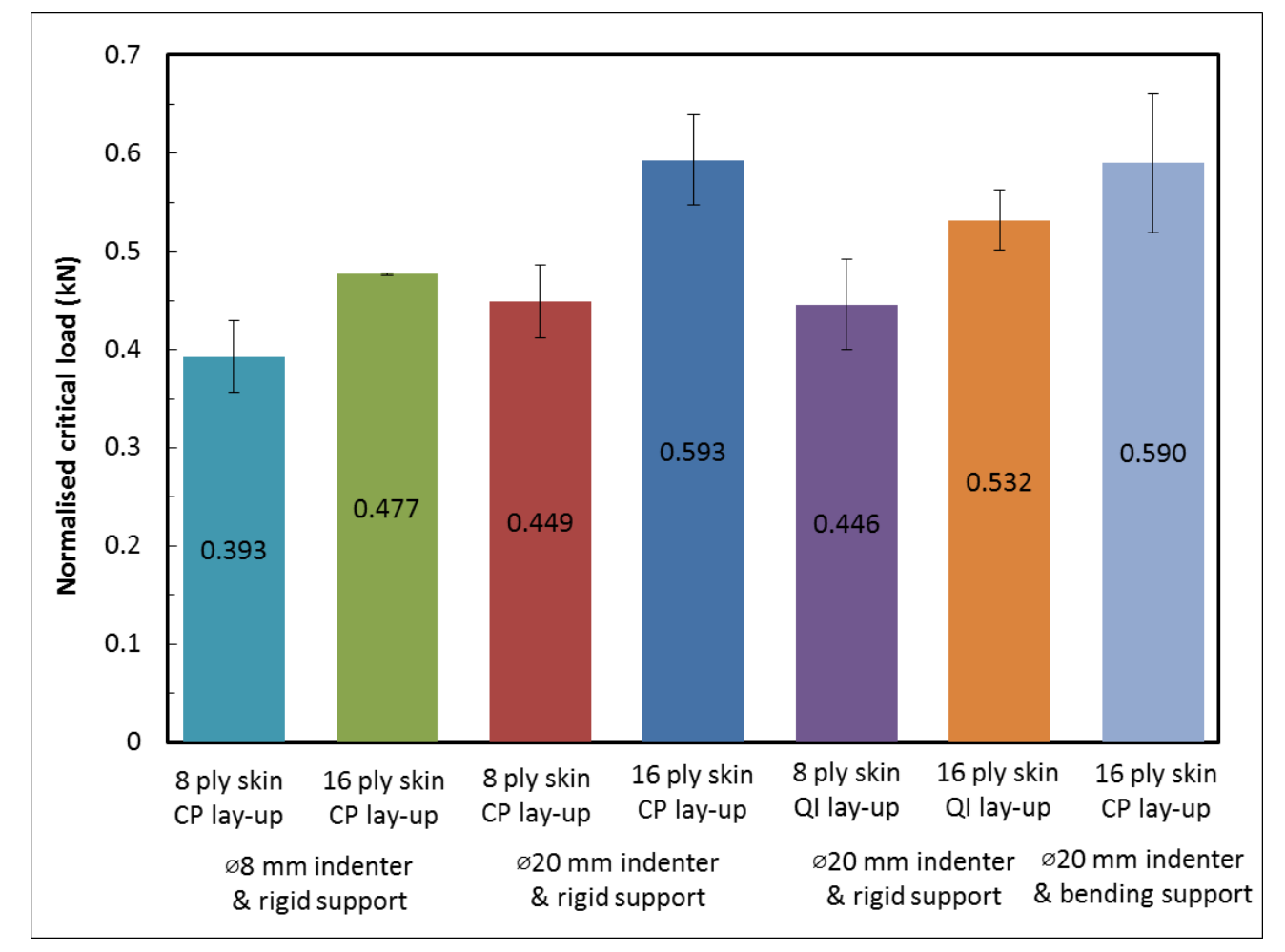

Fig. 13. Effect of increasing the thickness of the loaded skin on indentation behaviour 


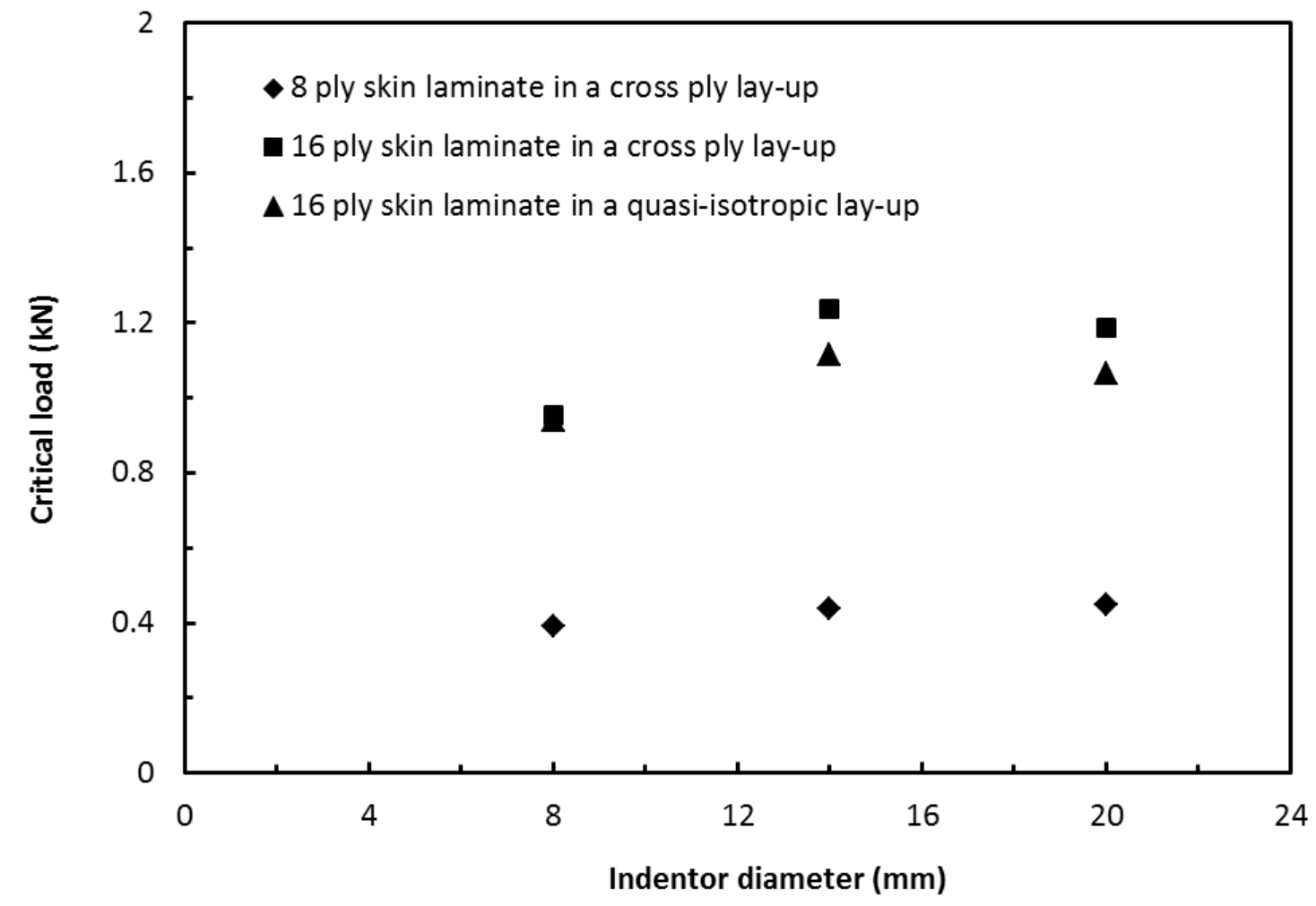

Fig. 14. The effect of increasing the loader diameter on damage characteristics in sandwich panels 